\title{
Castelnau-de-Brassac
}

Statue-Menhir d'Al Faux (Le Teil Bas)

\section{Pierre Nègre}

\section{(2) OpenEdition \\ 1 Journals}

Édition électronique

URL : http://journals.openedition.org/adlfi/10969

ISSN : 2114-0502

Éditeur

Ministère de la culture

Référence électronique

Pierre Nègre, «Castelnau-de-Brassac », ADLFI. Archéologie de la France - Informations [En ligne], Midi-

Pyrénées, mis en ligne le 01 mars 1997, consulté le 01 mai 2019. URL : http://

journals.openedition.org/adlfi/10969

Ce document a été généré automatiquement le 1 mai 2019.

(C) Ministère de la Culture et de la Communication, CNRS 


\title{
Castelnau-de-Brassac
}

\author{
Statue-Menhir d'Al Faux (Le Teil Bas)
}

\section{Pierre Nègre}

Date de l'opération : 1990 (SU)

Inventeur(s) : Nègre Pierre

1 Découverte en 1989 par M. Sompayrac, propriétaire du champ d'où elle fut retirée, la statue-menhir d'Al Faux fut authentifiée par P. Nègre et D. Gasc. Le lieu de découverte correspond à l'emplacement d'origine de son érection. Il se trouve sur la convexité d'un versant à forte pente, dans un ensellement. Le mégalithe était couché sur sa face avant.

2 Il s'agit d'une dalle ovalaire en granite (Fig. $\mathrm{n}^{\circ} 1:$ La statue-menhir après relevage), longue de $1,70 \mathrm{~m}$, large de $1 \mathrm{~m}$ et d'épaisseur variable $(0,15 \mathrm{~m}$ à $0,30 \mathrm{~m})$. On distingue sur la face principale de cette statue-menhir de type masculin: la ceinture, la boucle qui lui est associée, les deux jambes accolées, le baudrier et « l'objet », enfin les yeux et le nez.

3 Le lieu où elle gisait a été repéré avec précision. La prospection de la surface du sol a permis de récolter à proximité quelques éclats de silex dont certains ont visiblement subi l'action du feu.

4 La fouille d'une quinzaine de mètres carrés s'est soldée par l'absence totale de structures évidentes. Seuls quelques débris charbonneux ont été repérés à l'emplacement de la statue-menhir. De la fouille ont été retirées deux dalles de schiste noduleux apportés par l'homme à une époque indéterminée.

\section{ANNEXES}


Fig. $\mathrm{n}^{\circ} 1$ : La statue-menhir après relevage

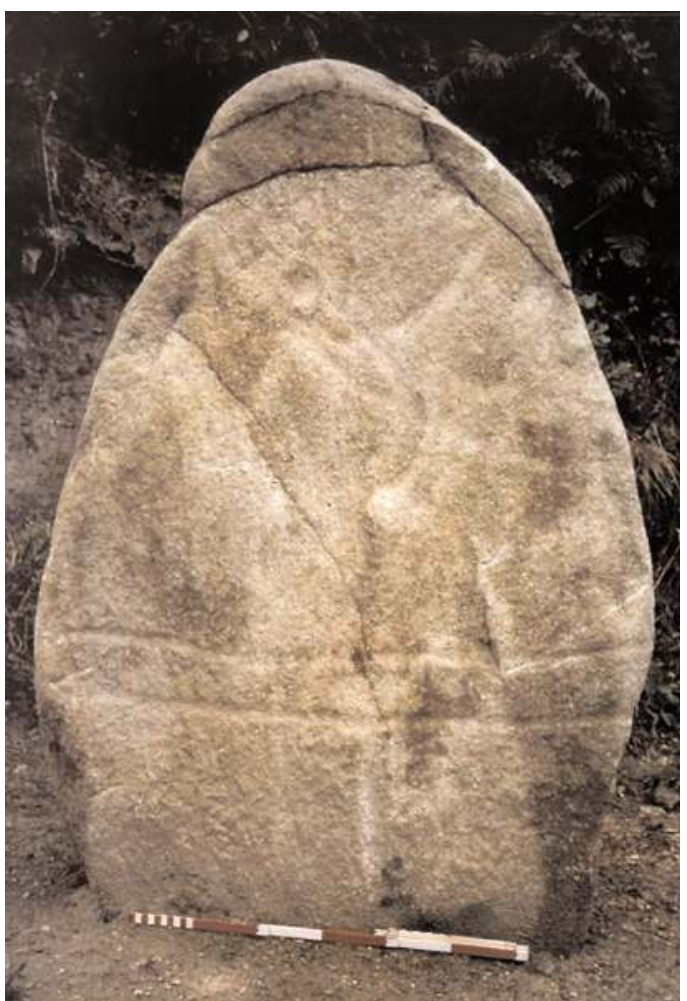

Auteur(s) : Nègre, Pierre. Crédits : Gl, 1997 - CNRS Editions, 1998 (1997)

\section{INDEX}

Index chronologique : Chalcolithique, Néolithique final

Index géographique : Midi-Pyrénées, Tarn (81), Castelnau-de-Brassac operation Sauvetage urgent (SU) 